\title{
ESTILOS DE LIDERANÇA APLICADOS AO SEGMENTO DO CAFÉ: UM EXEMPLO NO SUL DE MINAS/BRASIL
}

\section{LEADERSHIP STYLES APPLIED TO THE COFFEE SEGMENT: AN EXAMPLE IN MINAS SOUTH /BRAZIL}

\author{
Otávio Barbosa Baldoni ${ }^{1 *}$, Alessandro Messias Moreira², Edna Maria Querido de Oliveira Chamon ${ }^{3}$ \\ ${ }^{1}$ Mestre, Mestrado em Gestão e Desenvolvimento Regional, Centro Universitário do Sul de Minas - UNIS-MG, Varginha, MG, Brasil, \\ baldoniotavio@yahoo.com.br \\ 2 Doutor, Mestrado em Gestão e Desenvolvimento Regional, Centro Universitário do Sul de Minas - UNIS-MG, Varginha, MG, Brasil, \\ alessandromoreira@unis.edu.br \\ ${ }^{3}$ Doutora, Universidade Estácio de Sá - UNESA, Rio de Janeiro, Brasil; Universidade de Taubaté - UNITAU; Mestrado em Gestão e \\ Desenvolvimento Regional UNIS-MG, Varginha, MG, Brasil, edna.chamon@gmail.com \\ ${ }^{*}$ Autor de correspondência
}

\section{Resumo}

Este trabalho analisa os estilos de liderança entre os produtores de café do Município de Boa Esperança - MG. Tal abordagem se justifica, visto que, esse produto tem uma grande representatividade em Minas Gerais, sendo o estado brasileiro com o maior número de lavouras de café (CONAB, 2019), em âmbito estadual, o sul do estado destaca-se por ter um grande volume de lavouras de café. O município de Boa Esperança foi escolhido, pois ocupa o terceiro lugar do estado no ranking de produção. O objetivo é identificar os estilos de liderança dos produtores de café, visto que a liderança se faz presente em todas as organizações nas quais o sujeito se insere. Este trabalho teve abordagem qualitativa e utilizou de entrevistas para a coleta de dados. O tratamento e análises dos dados foram realizados com o auxílio do software Iramuteq e o Excel para elaboração dos gráficos. O presente demonstrou que existe uma forte presença dos estilos de liderança transformacional e transacional entre os produtores entrevistados, cada hora um estilo se sobressaindo, dependendo do contexto em que o líder está inserido.

Palavras-chave: Liderança. Café. Boa Esperança. Sul de Minas. Fazenda.

\begin{abstract}
This work analyzes leadership styles among coffee producers in the Municipality of Boa Esperança - MG. This approach is justified, since this product is highly representative in Minas Gerais, being the Brazilian state with the largest number of coffee plantations (CONAB, 2019), at the state level, the south of the state stands out for having a large volume of coffee plantations. The municipality of Boa Esperança was chosen because it ranks third in the state in terms of production. The objective is to identify the leadership styles of coffee producers, since leadership is present in all associations in which the subject belongs. This work was a qualitative study and used location for data collection. The treatment and analysis of the data were carried out with the help of the Iramuteq software and Excel for the elaboration of the graphics. The present study leadership and continuous that there is a strong presence of transformational and transactional leadership styles among the interviewed producers, each time a style standing out, depending on the context in which the leader is inserted.
\end{abstract}

Keywords: Leadership. Coffee. Boa Esperança. South of Minas. Farm

(C)UNIS-MG. All rights reserved. 


\section{INTRODUÇÃO}

Estudos sobre o fenômeno liderança existem desde os primórdios da civilização, porém ganharam visibilidade a partir do século XX (BASS, 2008). Sendo que, no final do referido século, tiveram transformações culturais no comportamento dos líderes, que de acordo com Chemers (2000), foi um período que teve um impacto a respeito do comportamento gerencial e a assimilação do que seria um líder ideal, é dado início então, um movimento para avaliar a relação entre o fenômeno da liderança e a cultura organizacional. Foi nesse período que surgiram os estilos de liderança transformacional e transacional, nos quais o primeiro é baseado na motivação de estímulo do líder para o liderado e o segundo é baseado no processo de trocas. De acordo com Avolio, Walumbwa e Weber (2009), são os estilos de liderança mais analisados nos últimos 20 anos.

Independente do estilo de liderança empregado, salienta-se que é a forma de liderar adotada pelo líder que irá direcionar o negócio. Assim, se é necessário, em uma organização, considerar a individualidade das pessoas que ali trabalham, se faz necessário que o gestor adote uma postura de liderança em conformidade com o perfil da sua equipe, para direcionar o andamento da organização. Neste sentido, a necessidade de identificar os tipos de líderes e quais estilos de liderança que os mesmos empregam é de crucial importância para a organização.

Considerando que a maior parte das pesquisas encontradas sobre o tema liderança são em organizações que funcionam em ambientes fechados, como escolas, empresas privadas, bancos e organizações públicas, decidiu-se investigar quais os estilos de liderança predominante entre produtores de café, que são líderes que gerenciam fazendas caracterizadas por ambientes abertos. O objetivo, portanto, é identificar os estilos de liderança dos produtores de café, uma vez que a liderança se faz presente em todas as organizações nas quais o sujeito se insere, empresas, propriedades rurais, comunidades, além de gerar informações importantes sobre a cafeicultura e os produtores para o município e ser uma fonte de informação para estudos futuros.

Foi escolhido o município de Boa Esperança -MG, visto que ele está localizado no Sul do estado de Mineiro, o qual se avulta por ser o maior produtor do Brasil. De acordo com a EMATER (2019), Boa Esperança possui 19.441 hectares em lavouras e café, ocupando o terceiro lugar dentre as cidades do Sul de Minas.

Dentre os estilos de liderança abordados nas entrevistas com os produtores rurais, temos o estilo de liderança transacional, o estilo transformacional e o estilo Laisse-faire, foi pedido aos participantes que respondessem um bloco de perguntas relacionados ao tema, contendo questões relativas à cafeicultura e um roteiro de perguntas sobre liderança que foi adaptado de um questionário semiestruturado de estilos de liderança produzido por Avolio e Bass (2004).

\section{FUNDAMENTAÇÃO TEÓRICA}

\subsection{O Café no Município de Boa Esperança - MG}

No final do século XVIII houve uma queda na extração do ouro no Estado de Minas Gerais, fazendo com que os habitantes procurassem uma nova atividade para garantir a subsistência, dedicando, portanto, a atividade agrícola, criação de gado e produção de gêneros voltados para o mercado interno (FILETTO; ALENCAR, 2001).

Um fator que colaborou para o início e desenvolvimento da agricultura no Estado Mineiro foi a produção de café que já existia no Rio de Janeiro e Vale do Paraíba. De acordo com relatos históricos encontrados, o grão foi levado até a região Sul de Minas por mediação dos tropeiros 
(VALVERDE, 1967). A concretização dessa produção de café no referido estado foi possível a partir de empresários comerciantes que por meio de suas atividades foram capazes de acumular capital e depois se interessaram pela produção do café (FURTADO, 2000).

No início, a produção do grão era destinada para o consumo interno. Durante muitos anos a cafeicultura não tinha uma produção significativa, se comparado com outros estados, principalmente o Rio de Janeiro (SINGER, 1977). Apesar de a cafeicultura Sul Mineira adquirir expressividade e incremento de produção no fim do século XIX e no início do século XX a produção nacional, já era considerada mundialmente a maior desde 1830, período em que o Brasil já tinha uma posição de destaque.

A agricultura no município de Boa Esperança seguiu, ao fim do século XIX, os rumos da expansão cafeeira, no qual deixou-se de produzir outros gêneros alimentícios, uma vez que na década anterior os preços internacionais do café estavam em expansão, conforme apresentado por Gremaud, Saes e Júnior (2008, p. 47): “De 1885 a 1890, o preço internacional do café cresceu rapidamente, aumentando também o valor total das exportações de café no Brasil (cuja média entre 1880 e 1884 era de 11 milhões de libras esterlinas e atinge 19 milhões em 1899)".

Atualmente, o município de Boa Esperança ocupa a terceira posição no ranking de área plantada em café das cidades do Sul de Minas, com 19.441 hectares de lavouras, de acordo com relatório do Portal do Café de Minas, ficando atrás das cidades de Campos Gerais que ocupa o primeiro lugar e o segundo é ocupado pela cidade de Três Pontas (EMATER, 2019). A respeito da produção, o município fechou o ano de 2017 com um saldo de 327.375 sacas de $60 \mathrm{~kg}$ de café arábica, já o ano de 2018 que foi considerado um período de bienalidade positiva, o saldo foi de 497.500 sacas. Com esse resultado, o município ocupa a terceira posição no ranking de produção de café entre as cidades do Sul de Mineiras, sendo considerado, portanto, uma cidade que tem uma representatividade quando se trata da produção de café.

No próximo item serão apresentadas as teorias contemporâneas sobre liderança, com destaque para liderança transformacional e transacional que foram abordadas nesse estudo.

\subsection{Estilos de Liderança}

No que se refere à liderança, não existe uma definição única e universal, mas existem abordagens que são mais utilizadas pelos autores. Com base em pesquisas sobre o tema em questão, realizadas no século $X X$, uma das principais definições sobre esse termo, foi feita por Stogdill (1948), que dizia que o vocábulo liderança era o processo de influenciar membros de um grupo organizado em suas atividades com objetivo de atingir as metas.

Observando o histórico das teorias sobre liderança, identificou-se, no início, a teorias dos traços entre os anos 1904 e 1948, com foco nas qualidades pessoais do líder BERGAMINI (1994). Em seguida, o modelo de dois fatores que influenciou diversas pesquisas para compreensão dos comportamentos de liderança (NORTHOUSE, 2010). Posteriormente, desenvolveram-se estudos sobre as teorias situacionais nos anos 70, buscando identificar o que os líderes faziam e quais os comportamentos dos líderes eficazes (NORTHOUSE, 2010). Em seguida, surgiram as teorias contingenciais, buscando identificar o fator situacional e prever qual melhor estilo de liderança para a circunstância, com destaque para o modelo de Fiedler (NORTHOUSE, 2010). Por último a abordagem caminho/meta que foi umas das primeiras abordagens a explicar como as tarefas e as características dos liderados se pautam com a liderança (NORTHOUSE, 2010).

Todas essas teorias tiveram grande contribuição no avanço das pesquisas sobre liderança, porém não esgotaram o tema. Foram necessárias outras abordagens para compreender os novos 
tempos, surgindo, então, as teorias contemporâneas sobre liderança, com destaque para liderança transformacional e transacional que serão abordadas nesse estudo.

\subsection{Abordagens Contemporâneas sobre Liderança}

No final do século XX houve algumas mudanças culturais no comportamento dos líderes, que segundo Chemers (2000), foi um momento em que ocorreu um impacto sobre o comportamento gerencial e a assimilação do que seria um líder ideal para cada tipo de ambiente, começa um movimento para analisar a relação entre o fenômeno da liderança e a cultura organizacional. Esse período ficou marcado pela forte presença dos estilos de liderança transacional e o estilo de liderança transformacional que foram caracterizados por uma mistura do movimento contingencial e movimento de comportamento e por último o estilo de liderança carismática (BASS, 1999).

A liderança transacional é baseada em uma metodologia de trocas, estabelecendo sempre algum tipo de recompensa caso o funcionário atinja as metas que foram estabelecidas, preocupando sempre com o desenvolvimento da organização (NORTHOUSE, 2010). Segundo Bass (2008), a liderança transacional está fundamentada em três grandes comportamentos: a) instruir sua equipe em relação aos preceitos de cada atividade a ser executada, que serão recompensadas se o funcionário cumprir o que foi exigido, situação essa que acaba fazendo com que eles só trabalhem quando tiverem algo em troca, deixando a tarefa de ser o objetivo principal da organização e passando a ser o meio de ganhar algum benefício; b) gestão ativa, na qual o papel do líder é primar para que todas as normas estabelecidas sejam cumpridas pelos liderados; e c) gestão por exceção, na qual o líder só toma alguma atitude ou decisão quando os resultados esperados não são atingidos, ou quando se tem desvio dos padrões preestabelecidos.

Como um contraponto à Liderança transacional, surge a Liderança Transformacional, termo criado por Downton (1973). Segundo Northouse (2010), a liderança transformacional não trata o subordinado de forma individual e sim prioriza os interesses coletivos. A principal característica que define o estilo transformacional é o relacionamento e aproximação que esse estilo de liderança tem em relação ao líder e o seu seguidor, a liderança transformacional diz que o seguidor acaba produzindo mais e gerando melhores resultados (BASS, 2008; CALAÇA; VIZEU, 2015). Os líderes transformacionais comumente conseguem extraordinários resultados, motivando seus seguidores por meio de exemplos e atitudes (HATER; BASS, 1988, p. 695). Os líderes utilizam da transparência, feedback e relação de ética para conseguirem grande influência sobre os seus subordinados, consequentemente conseguem resultados acima de suas expectativas (HU et al., 2012).

Baseado nas pesquisas de Burns e House, em 1985, Bass publica um estudo formal a respeito da teoria da liderança transformacional. Bass e Avolio (1993), aprimoraram o modelo a partir de pesquisas investigativas, desenvolvendo uma proposta que foi denominada de Full Range Leadership Development ou desenvolvimento de liderança em larga amplitude. Desde então, as teorias de liderança transformacional e transacional deixam de ser interpretadas como opostas e passam a ser consideradas complementares. Nessa visão, o estilo de liderança transacional passou a ser compreendido de duas maneiras, a primeira delas é recompensa por contingente e o segundo recompensa pela exceção.

$\mathrm{Na}$ recompensa por contingente, os objetivos e as metas estão atrelados com as recompensas, as metas são definidas mutuamente entre líder e liderado e o liderado tem a função de oferecer recursos para os subordinados. Já a gerência pela exceção, existe em duas formas, na forma ativa, o líder acompanha metodicamente o trabalho de seus liderados, usa de feedback negativo para advertir os subordinados quando cometem erros. A forma passiva é considerada 
ineficiente, segundo os autores, visto que, o líder só tomará uma decisão, de forma passiva, quando perceber que as tarefas não estão sendo executadas conforme programado (BASS; AVOLIO, 1993).

Para Bass e Avolio (1993), líderes transformacionais motivam e estimulam seus subordinados a alcançaram o mesmo objetivo, além de contribuírem para que a criatividade e a proatividade sejam desenvolvidas. Além de terem confiança, os subordinados de um líder transformacional, sentem admiração e respeito o que acaba por gerar uma relação forte e duradoura. Os referidos autores, discorreram sobre os 4 elementos que constituem o componente transformacional, sendo eles: Influência idealizada, motivação inspiracional, estimulação intelectual e consideração individualizada.

A influência idealizada é vista como o nível mais alto da Liderança Transformacional. A conduta ética praticada pelo líder colabora para uma relação de respeito por parte dos liderados em relação ao líder. O respeito e a admiração pela pessoa do líder são muito fortes, ele é visto como alguém que nunca irá considerar suas necessidades acima das necessidades do outro, o que acaba fortalecendo mais sua ética e a moral. Estudos realizados por Bass e Bass (2008) consideraram que a Influência Idealizada tem uma forte relação com a Liderança Carismática.

A motivação inspiradora, o líder passa para sua equipe qual será o futuro da organização, encoraja e inspira sua equipe por meio de emoções. Através desse apelo emotivo que o líder consegue fazer seus seguidores atingir o objetivo proposto. Ele se mantém sempre otimista com relação ao futuro da organização e transmite isso para sua equipe com intuito de motivá-la. Comunica sempre com clareza, transmitindo confiança e despertando o espírito de equipe.

A estimulação intelectual, o líder estimula sempre a inovação, valoriza a criatividade de seus liderados. Ele tenta sempre estimular a imaginação e o aparecimento de novas ideias para solucionar os problemas de formas diferentes do cotidiano. Erros e falhas não são criticados, pelo contrário, o liderado é sempre motivado a testar ideias novas. Os líderes são respeitados pela capacidade de resolver os problemas de forma inovadora.

A consideração individualizada respeita as individualidades de cada liderado, o líder se comporta como um mentor. O líder se mostra disponível o tempo todo para ajudar e orientar cada indivíduo, de modo que, eles se desenvolvam, se realizem e atinjam seu pleno potencial. O líder utiliza do feedback individual para aproximar mais dos membros da sua equipe, conhecê-los melhor e identificar as necessidades individuais de cada um, só depois dessa interação ele conseguirá treinar a capacitar sua equipe de acordo com suas necessidades.

Segundo Bass (1999), os melhores líderes podem ter características de liderança transformacional e transacional ao mesmo tempo, pois, segundo o autor o comportamento transacional que foca na recompensa contingente, que transmite confiança e que é consistente, poderá contribuir para práticas de liderança transformacional. Enquanto, o líder transformacional que compartilha uma visão de futuro com sua equipe e trata cada membro da equipe como indivíduo, acaba ressaltando as características da liderança transacional em seu estilo. $\mathrm{O}$ autor conclui, portanto, que os dois estilos de liderança são importantes e complementares.

\section{MATERIAIS E MÉTODOS}

Para realização de uma pesquisa cientifica utilizam-se de métodos que possibilitam a verificação dos procedimentos do estudo (MINAYO, 2009). Essa pesquisa, que tem objetivo de investigar quais os estilos de liderança entre os produtores de café do município de Boa Esperança 
- MG, utilizou-se de um estudo transversal, pois analisou dados de uma amostra populacional específica, que foram coletados em um determinado período (HOCHMAN et al., 2005).

Caracteriza-se como uma pesquisa exploratória e descritiva, pois investigou o perfil dos produtores de café do município de Boa Esperança. Exploratória, pois teve como objetivo possibilitar uma visão geral sobre um determinado fenômeno, proporcionar maior familiaridade com o tema (GIL, 1999). A pesquisa tem abordagem qualitativa, pois teve uma abordagem interpretativa de dados, trabalhando com questões muito particulares e um nível de realidade que não pode ser quantificado, (DUARTE, 2002).

O instrumento utilizado foi o roteiro de entrevista, com intuito de verificar como esses cafeicultores pensam, planejam suas produções, agem no dia a dia do seu trabalho e obtêm informações sobre os seus comportamentos. As questões sobre liderança foram adaptadas de um questionário semiestruturado de estilos de liderança produzido por Avolio e Bass (2004), já utilizado em diversas pesquisas práticas no Brasil e Portugal (GONÇALVES, 2008). A entrevista é composta por uma série de perguntas elaboradas pelo pesquisador com a intenção de obter informações pertinentes para a pesquisa (GIL, 1999). Todas as entrevistas com os produtores foram gravadas, transcritas e posteriormente trabalhadas nos Software Iramuteq (Interface de $R$ pour les Analyses Multidimensionnelles de Textes et de Questionnaires) que consiste em uma interface visual fundamentada no software $R$ de análises estatísticas, ferramenta que possibilita criar categorias e descrever numericamente o conteúdo das entrevistas, por meio do método de lematização dos radicais das palavras e de sua organização em segmentos de textos (SOUZA et al, 2018).

O número de entrevistas não foi previamente definido, o critério utilizado foi o de saturação, que segundo Bauuer e Gaskell (2014), é o critério de finalização, pois a amostra permite ao pesquisador obter eficácia no seu estudo na medida em que fornece uma base lógica de partes de uma população sem que informações importantes sejam desconsideradas, caso contrário o projeto de pesquisa não teria fim. Por esse caminho, chegou-se em um número de 15 entrevistas, considerando como sujeitos produtores de café com lavouras localizadas no município de Boa Esperança - MG. As mesmas foram gravadas e na sequência transcritas para o formato textual, utilizando a ferramenta Microsoft Word $^{\circledR}$.

Por sua vez, compreendendo que a análise de dados textuais em grande volume, pode ser muito trabalhosa e pode apresentar algumas limitações, como por exemplo a interferência do pesquisador em relação ao objetivo da pesquisa. Optou-se, como forma de tentar reduzir o impacto dessa subjetividade, realizar a análise dos dados com apoio do IRAMUTEQ, um software considerado específico para análise de dados textuais (NASCIMENTO; MENANDRO, 2006; CAMARGO; JUSTO, 2013).

Após análise das entrevistas no IRAMUTEQ, o software gerou classes com suas intersecções e as palavras mais representativas em cada uma delas. A configuração das 5 classes geradas pelo IRAMUTEQ, foram divididas em 2 ramificações principais, o Subcorpus $A$, contendo apenas a classe 5 e o Subcorpus B, composto pelas classes 1, 2, 3 e 4. Posteriormente, foi realizada uma análise dos discursos, com objetivo de identificar quais estilos de liderança as falas se remetem, considerando as definições dos autores que constam no referencial teórico. 


\section{RESULTADOS E DISCUSSÕES}

\subsection{Caracterização da amostra das entrevistas}

Na Figura 1 é apresentado o perfil dos 15 produtores que participaram das entrevistas, no caso específico traz a identificação dos respondentes quanto ao Gênero.

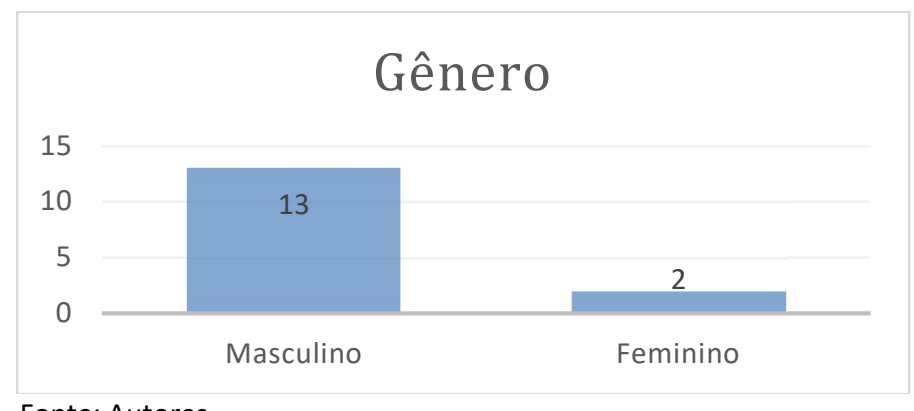

Fonte: Autores.

Figura1 - Gênero dos participantes das entrevistas

Dos quinze participantes das entrevistas, apenas 2 se identificaram como do gênero feminino, por sua vez, 13 deles se intitulam do sexo masculino, o que nos permite perceber que dentro os entrevistados, a presença masculina na cafeicultura é maior se comparado com feminino. Quanto ao tempo da cultura do grão, a Figura 2 apresenta os dados informados pelos entrevistados:

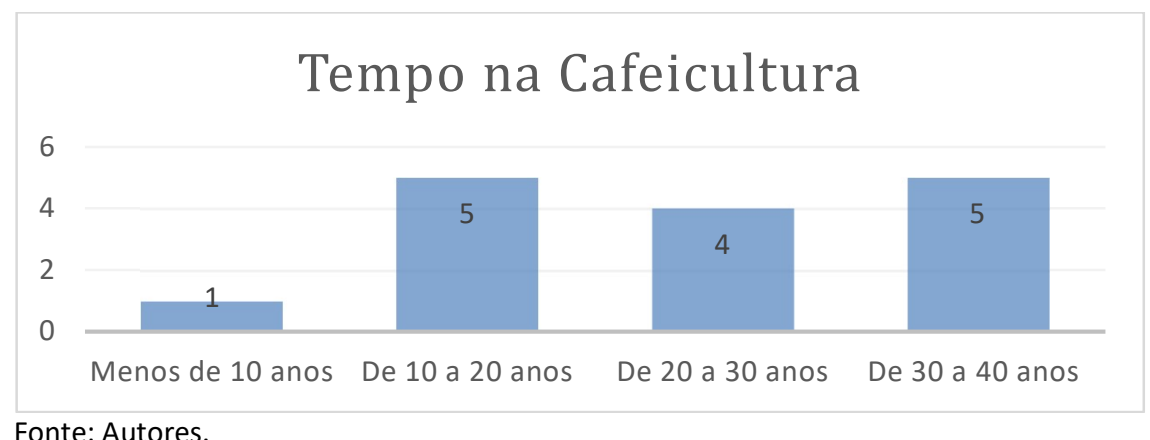

Figura 2 - Tempo na cafeicultura

Percebe-se que a maioria dos entrevistados estão na atividade por mais de 10 anos e 5 deles por mais de 30 anos. Um período considerado longo e que pode estar relacionado com a questão familiar, visto que a maioria são filhos de produtores de café e afirmaram ter herdado alguma propriedade dos pais. Por sua vez, a Figura 3 traz a fonte de renda dos sujeitos da pesquisa.

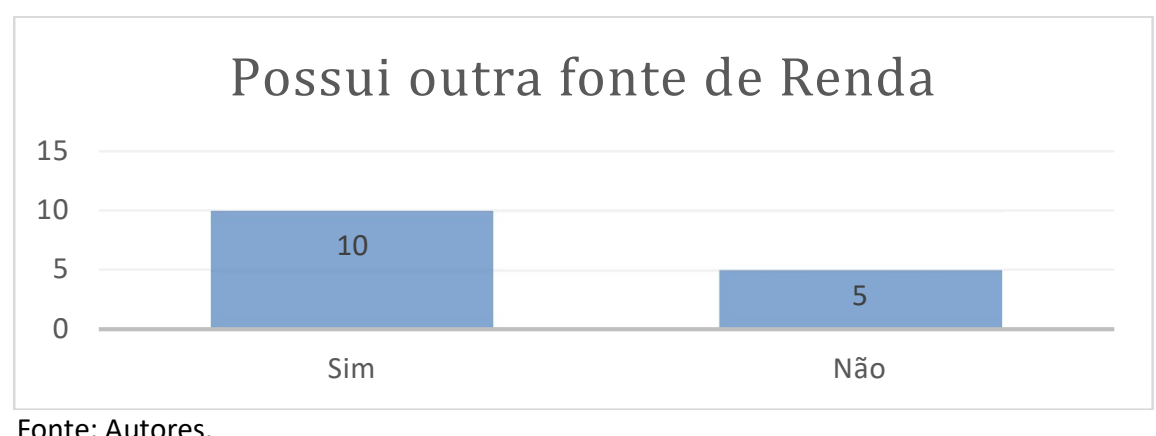

Fonte: Autores.

Figura 3 - Fonte de Renda 
Um ponto que chamou a atenção, foi o indicado por 10 sujeitos que alegaram possuir outra renda, por sua vez apenas 5 produtores afirmaram que retiram seu sustento exclusivamente das lavouras de café, ou seja, $66 \%$ da amostra afirmaram ter outra renda, sendo que 6 deles possuem outra renda que está ligada direta ou indiretamente com o agronegócio, pois dentre as respostas obtidas, apresentaram: criação de gado, silo de milho, produção de leite, consultor agronômico e conselho em cooperativa de credito. A Figura 4 traz informações quanto ao tamanho da propriedade:

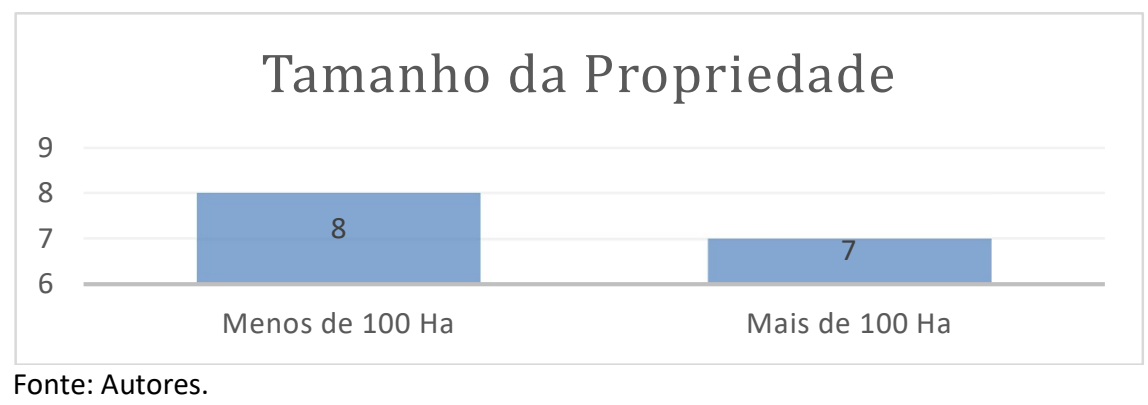

Figura 4 - Tamanho da propriedade

Dentre os entrevistados, 53,33\% disseram possuir menos de 100 hectares de terra, ou seja, podem ser considerados agricultores familiares de acordo com a Lei no 11.326/2006, que considera agricultor familiar àquele que exerce atividades no meio rural, possui uma propriedade de até quatro módulos fiscais, emprega mão de obra da própria família e tem porcentagem mínima de renda originada de atividades econômicas de suas terras (BRASIL, 2006).

\subsection{Análise das Entrevistas}

Para realização da análise textual das entrevistas realizadas, utilizou-se o software IRAMUTEQ, ou seja, o material de transcrição das 15 entrevistas foi trabalhado e agrupado em um único corpus, utilizando-se as linhas de comando necessárias para a ferramenta, conforme manual do software (CAMARGO; JUSTO, 2013), sendo que cada entrevistado ganhou um número, sendo identificados por: $* * * * *$ ind_01, $* * * * *$ ind_02, e assim sucessivamente. Foram criados códigos para identificar características como, idade, sexo, escolaridade, local de residência e quantidade de terras em hectares, conforme o seguinte exemplo: “*****id_x*sex_x*escola_x*local_x *hec_x". De modo a não identificar os respondentes, os mesmos foram classificados em números de 01 a 15. Objetivou-se com as entrevistas, identificar quais estilos de liderança são predominantemente adotados pelos cafeicultores.

O corpus gerou 290 segmentos de texto - ST, com 10.416 ocorrências de palavras (palavras, formas e vocábulos), sendo 1.529 formas aproveitadas com rejeição de pronomes, conjunções e preposições. Após o tratamento, o software gerou para o corpus 5 classes: classe 1, com 47 ST de um total de 212 (22,17\%); classe 2, com 34 ST (16,04\%); classe 3, com 52 ST (24,53\%); classe 4, com 39 ST $(18,4 \%) ;$ e, por fim, a classe 5 , com 40 ST $(18,87 \%)$. Na Figura 5 podemos ver as palavras que mais apareceram em cada classe.

A configuração das 5 classes foi dividida em 2 ramificações principais, o Subcorpus A (valores), contendo apenas a classe 5 , seguindo do Subcorpus B (Comportamentos), composto pelas classes 1, 2, 3 e 4. No subcorpus A, nomeado: valores, notou-se que os respondentes relataram atitudes e posturas de um líder. 


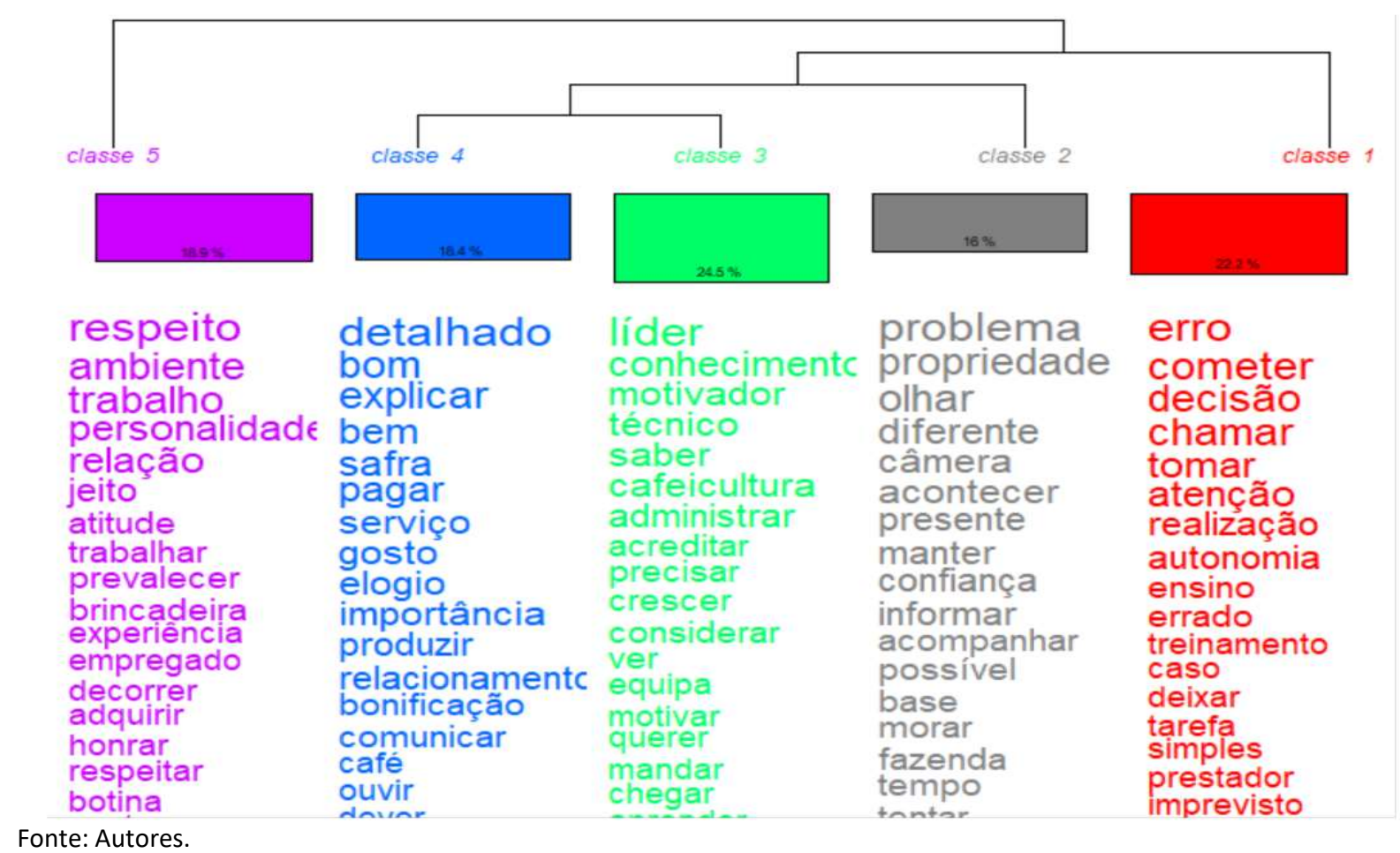

Figura 5 - Classes de palavras

\section{Classe 5 - Valores de Um líder}

A classe 5, que compõe esse subcorpus, foi nomeada como "Valores de um líder", pois, a classe trouxe discursos relacionados com as condutas que os respondentes julgaram importantes para conquistar respeito no ambiente de trabalho e questões como comportamentos, conhecimentos tácitos e traços de liderança. O conhecimento tácito é entendido como o resultante da experiência no trabalho e praticamente se confunde com a concepção de competência no taylorismo/fordismo (KUENZER, 2003). Dentre as atitudes apontadas pelos respondentes para conquistar respeito no ambiente de trabalho, as principais foram: respeito, educação, honestidade e ter postura na hora da fala.

Os fragmentos de textos relacionados a classe 5, foram categorizados como "Valores de um Líder". Essa classe portando foi subdividida em duas categorias, com objetivo de facilitar a interpretação dos dados. A primeira categoria da classe 5 foi nomeada como "atitudes" e a segunda como "maneira de trabalhar". Os discursos, portanto, representam "Atitudes" de um líder (Classe 5), conforme Figura 6.

Esses discursos, enfatizando a ética e o respeito para com os trabalhadores, corroboram com a definição de líder transformacional de Isidro-Filho e Guimarães (2008), os mesmos argumentam que líderes transformacionais utilizam da ética e da transparência para conseguirem confiança e respeito do grupo. 
Educação é a primeira atitude, depois é respeitar as limitações das pessoas, cada profissional tem um tipo de limitação e tentar ao máximo ser companheiro da sua equipe (SUJEITO 5).

A principal é você cumprir o que você fala, dar o exemplo antes de cobrar e mostrar sempre o objetivo da empresa (SUJEITO 7).

Educação, acho fundamental você ter respeito pelo outro para que ele te respeite também (SUJEITO 10).

Eu acho que para você ter respeito você precisa ser honesto, a honestidade pra mim é uma das coisas mais importantes que tem. Eu ensinei isso para os meus filhos desde criança (SUJEITO 12).

Controlar as palavras que você fala, saber escutar as pessoas, não corrigir em público e honrar sempre suas obrigações (SUJEITO 9).

Fonte: Autores.

Figura 6 - Atitudes de um líder (Classe 5)

Com relação aos traços de liderança e ao conhecimento adquirido por meio da experiência profissional, a maioria dos entrevistados disseram que sua "Maneira de trabalhar" tem relação com a personalidade e com o conhecimento tácito, sendo esse um tipo de conhecimento difícil de ser formalizado, pois, advém das experiências e modelo mental dos indivíduos (NISSEN; KAMEL; SENGUPTA, 2000). Os discursos dos sujeitos que ilustram a "maneira de trabalhar" de um líder (Classe 5) são apontados na Figura 7.

Acho que a soma das duas coisas. Você tem sua personalidade e tem ferramentas de gestão que você aprende a usar no decorrer da vida, mas cada um usa essas ferramentas de acordo com suas experiências e sua maneira de trabalhar (SUJEITO 9).

Acho que o meu jeito de trabalhar tem a ver com a personalidade e com as coisas que eu aprendi no decorrer da vida. Mas acho que tem muito a ver com o vínculo familiar também (SUJEITO 13).

Com as duas. Isso depende da situação, tem hora que a personalidade prevalece e tem hora que é a parte técnica que vai prevalecer (SUJEITO 2).

Acredito ser as duas coisas. Depende das situações e dos eventos que a gente enfrenta (SUJEITO 4).

Experiências, sem dúvida. Você vai “apanhando" e vai melhorando. Quando eu comecei a trabalhar eu era muito nervoso (SUJEITO 5).

Fonte: Autores.

Figura 7 - Maneira de trabalhar (Classe 5)

Essas falas elencadas, se remetem ao desenvolvimento e formação de líderes transfomracionais, pois de acordo com Bass e Avolio (1993), fatores historicos podem influenciar na formação de um líder transacional, visto que essa formação se da por meio de experiencias vividas e treinamentos que o lider possa vir a participar. 
Após as análises dos discursos desses sujeitos, identificou-se que os mesmos adotam posturas e comportamentos que contribuem para o resultado da liderança em seu processo de gestão, pois segundo Turano e Cavazote (2016), para que um líder tenha êxito em sua jornada, ele precisa se adequar no ambiente o qual ele está inserido, manter uma boa convivência com os integrantes da sua equipe e adotar determinados comportamentos que são de acordo com a situação.

Em seguida temos o subcorpus Comportamentos (B), esse se contrapõe ao subcorpus A que é composto pela classe 5 . No subcorpus comportamentos (B), temos a relação entre as classes 3 e 4, denominadas "O que é ser líder" e "Orientação" respectivamente. Assim como, temos as classes 1 e 2, denominada de "Tomar decisão", classe 1, e "Controle", classe 2.

\section{Classe 4 - Orientação}

Em continuidade ao Subcorpus B denominado Comportamento, temos a Classe 4, que foi chamada de "Orientação", em que as palavras que mais se sobressaíram foram: "serviços", "safra", "pagar", "elogio", "explicar", "detalhado" e "importância". Nessa classe, os pontos que mais se destacaram foram a importância de explicar e detalhar um serviço e a recompensa por serviços bem executados, seja por meio de pagamentos extra ou somente elogios.

Os respondentes, cujos discursos compuseram essa classe, dizem explicar os serviços de forma clara e detalhada e ainda complementaram dizendo que consideram ser necessário uma boa explicação para que a tarefa seja bem executada.

Os discursos dos sujeitos que ilustram a "Orientação" (Classe 4) podem ser observados na Figura 8:

[...] gosto de explicar a importância de adubar uma lavoura, a importância de um bom manuseio do café no terreiro, falo que isso é fundamental para conseguir bons resultados no final da safra (SUJEITO 5).

[....] a gente comunica com eles o tempo todo, conforme eu comentei anteriormente, é passado para eles os prejuízos que um erro pode causar, assim como, os benefícios que podemos alcançar se eles se esforçarem um pouco mais (SUJEITO 7).

[...] sempre tenho diálogo dou liberdade para eles expressarem e gosto de trocar ideias explico de forma detalhada como cada tarefa precisa ser feita e é isso que eu mais cobro na minha propriedade (SUJEITO 4).

Eu tento fazer o meu relacionamento com os funcionários ser o melhor possível muitas vezes a gente não agrada, mas eu tento eu sempre explico as tarefas de forma detalhada e acho muito importante fazer isso (SUJEITO 5).

Fonte: Autores.

Figura 8 - Orientação - Classe 4

Os trechos acima se rementem ao estilo de liderança transformacional, pois os líderes dizem explicar de forma detalhada como realizar um serviço e o motivo de executar aquela tarefa, além de estimular o atingimento de metas e de acordo com Oliveira et.al (2015), o líder transformacional tem o papel de estimular melhorias, alcance de resultados e manter uma boa comunicação. 


\section{Classe 3-O que é ser Líder}

A classe 3, foi denominada como "O que é ser líder", pois, englobou termos sobre liderança, como os respondentes se enxergam líderes e as questões relacionadas com "ter conhecimento técnico" das atividades nas quais os entrevistados lideram. As palavras que mais se fizeram presentes nessa classe foram: líder, conhecimento, saber, motivador, cafeicultura e administrar.

A Classe 3 foi subdividida em 2 conjuntos de fragmentos de texto, onde o primeiro foi denominado "Ser líder" e o segundo "Conhecimento técnico". Os discursos dos sujeitos que ilustram a "Ser líder" (Classe 3) são descritos na Figura 9.

Acredito que um bom líder precisa ser um bom administrador (SUJEITO 2).

Um líder tem que impulsionar sua equipe, sempre, mesmo nos momentos difíceis, o líder tem que achar solução para as coisas e trabalhar de forma que ele não deixe o sistema parar (SUJEITO 5).

Um líder tem que saber todos os serviços da empresa, precisa saber mandar, precisa ser sábio, ter conhecimento técnico das tarefas que você administra (SUJEITO 8).

No meu ponto de vista, um líder precisa ser criativo e empreendedor (SUJEITO 4).

Primeiro para ser um líder você precisa dar o exemplo e precisa estar engajado no negócio e ter um objetivo definido, saber de onde você está partindo e para onde você vai, onde você pretende chegar é o mais importante (SUJEITO 7).

Um líder precisa saber coordenar seus subordinados e motivá-los para atingir o objetivo comum do negócio (SUJEITO 9).

Fonte: Autores.

Figura 9 - Ser líder - Classe 3

Com base nas respostas obtidas, é possível apreender a partir dos discursos dos entrevistados, algo que está diretamente ligado com o conceito de liderança descrito por Turano e Cavazote (2016). Esses autores afirmam que liderar é um processo de influência dos líderes para com os seus seguidores, com objetivo de atingir uma meta pré-estabelecida. Assim, reafirma-se um dos principais conceitos que fora definido no século XX por Stogdill (1948), que preconizava que a liderança era definida pelo processo de influenciar as atividades de um grupo organizado em seus esforços com objetivo de atingir as metas.

Outra constatação nos discursos dos entrevistados acima, foi a presença do estilo de liderança transformacional nos discursos dos sujeitos 5 e 7, quando eles dizem que um líder, precisa impulsionar sua equipe e ser o exemplo. Essas falas se remetem ao conceito do estilo transformacional definido por Hater e Bass (1988), que diz:

[...] a dinâmica da liderança transformacional envolve forte identificação pessoal com o líder, juntando-se em uma visão compartilhada do futuro, que vai além da troca do auto interesse e de recompensas para o cumprimento das tarefas (HATER; BASS, 1988, P. 695).

O líder transformacional estimula o desenvolvimento intelectual do funcionário promovendo a mudança e fazendo com que o funcionário defenda a organização de forma a garantir seu futuro. 
Além de questões como "Ser líder", essa classe trouxe discursos relacionados com ter "Conhecimento técnico" sobre as atividades que o líder gerencia, no caso desse estudo, ter conhecimento técnico sobre a cafeicultura. Os respondentes apontam ter conhecimento técnico sobre a cafeicultura, e alguns falaram que é impossível saber tudo, pois, as pesquisas estão em constante evolução e, consequentemente, o produtor precisa estar sempre em busca de informação. Alguns respondentes inclusive argumentaram que o conhecimento precisa ser atrelado a uma boa administração, dizendo que o conhecimento técnico por si só, não garante uma boa gestão do negócio. Os discursos que ilustram a "Conhecimento técnico" (Classe 3) podem ser observados na Figura 10.

Eu acredito ter conhecimento técnico de grande parte da cafeicultura, mas estamos sempre aprendendo, é impossível alguém saber tudo (SUJEITO 12).

Acredito que seja importante sim, ter conhecimento técnico, mas antes de tudo você precisa ter o instinto de saber administrar, se você sabe administrar você adquire o conhecimento de tudo (SUJEITO 3).

Conhecimento técnico eu tenho parcial, mas acredito ter domínio da parte operacional e gerencial e eu acho que é mais importante saber gerenciar do que conhecer a técnica do serviço (SUJEITO 4).

Eu tenho bastante conhecimento técnico sobre a cafeicultura, mas não posso dizer que sei tudo, estou sempre aprendendo. Tem um filosofo, acho que é o Sócrates que diz: 'só sei eu nada sei (SUJEITO 14).

Fonte: Autores.

Figura 10 - Conhecimento técnico - Classe3

Alguns produtores argumentarem que o estilo de gerenciar é mais importante que deter o conhecimento técnico da atividade, porém a teoria confronta esse argumento ao dizer que para um líder obter êxito em sua função ele necessita de domínio da atividade que administra (TURANO; CAVAZOTE, 2016).

A principal abordagem da classe 3 foi sobre o que é ser líder e o conceito de líder para os entrevistados. Ao analisar os discursos dos entrevistados, foi possível perceber que esses produtores têm uma definição clara do que é ser líder, pois os conceitos por eles definidos conversam com a definição de liderança descrita por Turano e Cavazote (2016), que dizem: a liderança é um processo de influência, promove interação, atingimento de metas e processo de transformação.

\section{Classe 2 - Controle}

A classe 2, a qual foi nomeado como "Controle". As palavras que mais se fizeram presente nessa classe foram: "Problema", "Propriedade", "Diferente", "Câmera", "Acontecer", "Presente" e "Confiança", entre outras com menor grau de estatística.

Por meio dos segmentos de texto apontados, foi possível verificar que os produtores tentam estar presente em suas propriedades a maior parte do tempo, na ausência deles, não existe um meio ou uma ferramenta utilizada para deter controle de tudo que acontece na propriedade, a maioria disse ser "na base da confiança", ou seja, eles precisam confiar nos funcionários.

Os discursos que ilustram a "Controle" (Classe 2) são descritos na Figura 11. 
[...] muita informação que eu tenho da fazenda quando estou ausente é na base da confiança até porque eu não consigo ficar o tempo todo (SUJEITO 1).

Para acompanhar o que acontece na propriedade eu tento ser presente sempre que possível mas um pouco é na base da confiança (SUJEITO 5).

[...] acompanhar o que acontece na fazenda quando eu não estou é na base da confiança (SUJEITO 2).

[...]um pouco acaba sendo na base da confiança eu tento estar presente a maior parte do tempo, mas nem sempre é possível (SUJEITO 8).

Fonte: Autores.

Figura 11 - Controle - Classe 2

Alguns afirmaram contar com o auxílio de câmeras que são instaladas nos barracões e terreiro de café, porém essa tecnologia só permite o controle nas redondezas onde tem benfeitoria, não abrangendo as áreas onde estão as lavouras de café (Figura 12).

[...] tenho câmeras nos terreiros e aos arredores da fazenda e um pouco na base da confiança (SUJEITO 7).

Para me manter informada de tudo que acontece na fazenda eu tenho câmeras no terreiro nas lavouras eu não tenho esse controle (SUJEITO 3).

[...] nos terreiros de café e barracões eu tenho câmeras para olhar o serviço na época da safra e mais por segurança da propriedade também agora na lavoura não tem como ter controle (SUJEITO 1).

Fonte: Autores.

Figura 12 - Recurso de câmeras

A classe 5, está baseada no controle, na forma como os produtores fazem para ter domínio de suas propriedades e das atividades que nela acontecem. Ao analisar as falas que compõem essa classe foi possível identificar a forte presença do estilo de liderança transacional, pois de acordo com Bass (2008), a liderança transacional é baseada em três grandes comportamentos e os fragmentos de texto da classe 5 , se rementem a dois desses três comportamentos, um deles é a gestão participativa, onde o papel do líder é garantir que todas as regras por ele determinadas sejam cumpridas e o outro comportamento é a gesto por exceção, onde o líder só irá intervir quando os resultados não forem atingidos e os padrões por ele propostos forem quebrados.

\section{Classe 1 - Tomar Decisão}

Em continuidade ao Subcorpus B denominado Comportamento, temos a Classe 1, o qual chamamos de "Tomar Decisão". As palavras que se destacaram nessa classe foram: "Decisão", "Tomar", "Autonomia", "Ensino", "Tarefa", "Cometer", "Erro", "Chamar atenção" e "Treinamento". 
Para melhor entendimento da Classe 1, a mesma foi subdividida em 2 conjuntos de fragmentos de texto, onde o primeiro conjunto abrange questões relacionadas a "Autonomia" e o segundo conjunto "Erro".

Nesse subcorpus o destaque foi para importância da tomada de decisão, dar autonomia para o subordinado tomar decisão quando necessário bem como chamar atenção e treiná-lo caso o mesmo venha cometer algum erro ou falha. No que tange ao processo de tomada de decisão, os cafeicultores participantes da pesquisa, disseram conceder autonomia para seus subordinados tomarem decisões, somente em situações mais simples e rotineiras. Quando as situações são mais complexas, os subordinados precisam consultar o proprietário da fazenda antes de tomar a decisão.

Os discursos que ilustram a "Autonomia" (Classe 1) podem ser observados na Figura 13.

Eu sempre escuto opinião dos empregados dou autonomia para eles tomarem decisões simples e peço para me avisar depois (SUJEITO 10).

Tudo de negativo impacta no lucro final na verdade eu tento ensinar eles tomarem decisões diariamente com intuito de impulsionar eles pensarem e agirem conforme eu agiria (SUJEITO 5).

Eu dou autonomia parcial pra eles tomarem decisões, mas sempre que eles tomam a decisão eles precisam me comunicar qual decisão foi tomada e a justificativa". (SUJEITO 2).

[...] decisões menores eu dou autonomia para não enrolar o serviço para fazer com que as coisas fluem de maneira rápida (SUJEITO 5).

[...] já ensinei meus filhos tomarem decisão quando eu tenho que ir na cidade eles que ficam responsáveis e tem autonomia para tomarem a decisão (SUJEITO 11).

Fonte: Autores.

Figura 13 - Autonomia - Classe 1

Com relação ao erro, ou cometer alguma irregularidade, os respondentes demonstraram ser transparentes e objetivos, visto que eles procuram conversar imediatamente com o funcionário que errou, mostrar o erro, averiguar as causas que levaram aquele erro acontecer e das instruções necessárias para que aquele erro não se repita. Essa interpretação foi possível a partir dos relatos dos sujeitos (Figura 14) que ilustram a "Erro" (Classe 1):

Além de analisar o erro e explicar a maneira correta, alguns produtores disseram abordar os impactos financeiros que um erro pode causar, fazem isso com intuído de mostrar para o funcionário que ele é importante e que a função desempenhada por ele é relevante para que o resultado seja positivo.

Ao ler as falas que compõem a classe 1 , foi possível associá-las com um dos elementos que constituem a componente transformacional. O elemento consideração individualizada fala da disponibilidade do líder em ajudar e orientar cada membro de sua equipe e da necessidade de realizar feedbacks individuais com intuito de aproximar dos funcionários e ensiná-los quando necessário. 
Muitos erros são cometidos por falta de atenção então eu gosto de mostrar o erro para eles e explicar que tudo de errado que eles fazem gera um dano e esse dano vai impactar no resultado final (SUJEITO 5).

[...] quando um funcionário comete um erro na realização de uma tarefa a primeira coisa que eu faço é perguntar o que aconteceu porque ele fez aquilo posteriormente eu mostro que está errado e explico a maneira correta de fazer (SUJEITO 2).

Eu chamo o funcionário em particular para conversar questiono o porquê do erro e explico como precisa ser feito das próximas vezes (SUJEITO 9).

Gosto sempre de investigar o porquê do erro se foi falta de informação falta de atenção e analiso a gravidade do erro também pois tem erros que são mais simples e podem ser relevados agora erros mais graves são mais complicados e precisão ser solucionados (SUJEITO 7).

Eu gosto sempre de analisar se o erro foi proposital falta de atenção ou incompetência (SUJEITO 5).

Fonte: Autores.

Figura 14 - Erro - Classe 1

\section{CONCLUSÃO}

Diante dos dados apresentados, percebe-se que o café é um produto de grande destaque no município estudado, sendo que em sua maioria produtores do gênero masculino e $47 \%$ dos entrevistados disseram possuir menos de 100 hectares de terra, o que automaticamente os classifica como agricultores familiares.

Entre os 15 produtores que participaram da entrevista, 10 sujeitos que alegaram possuir outra renda, ou seja, $66 \%$ da amostra, sendo que 6 deles possuem outra renda que está ligada direta ou indiretamente com o agronegócio.

Os resultados nos permitem considerar que entre os produtores de café do município de Boa Esperança - MG, existe uma forte presença dos estilos transformacional e transacional, ou seja, o que vemos é uma combinação desses dois estilos. Dependendo do contexto, das pessoas envolvidas e das atividades a serem desempenhadas cada hora um estilo de faz presente, um se sobressaindo sobre o outro ou se complementando. Esse resultado consona com a teoria de Northouse (2009), de acordo com o autor, a liderança transformacional não substitui a liderança transacional, o estilo transformacional complementa o estilo transacional em algumas situações.

O presente estudo teve uma contribuição para o desenvolvimento da pesquisa e da ciência nacional na área de liderança, visto que a pesquisa foi realizada em ambientes rurais, que são ambientes abertos e de grande extensão territorial, diferentes das pesquisas encontradas no referencial teórico desse estudo que foram em sua maioria realizadas em empresas, escolas, instituições públicas e bancos, que são organizações que funcionam em um ambiente fechado.

A principal limitação deste estudo foi a disponibilidade dos produtores em participar da pesquisa, visto que as entrevistas foram realizadas no período de pandemia da COVID 19, o que dificultou a coleta de dados. Diante disso, sugere-se para futuras pesquisas, ampliar a amostra, bem como, utilizar outra metodologia para fornecer mais informações sobre o assunto em questão. 


\section{REFERÊNCIAS}

AVOLIO, B. J.; BASS, B. M. Multifactor leadership questionnaire (TM). Menlo Park: Mind Garden, Inc, 2004.

AVOLIO, B. J.; WALUMBWA, F. O.; WEBER, T. J. Leadership: current theories, research, and future directions. Annual Review of Psychology, v. 60, n. 1, p. 421-449, 2009.

BASS, B. M.; AVOLIO, B. J. Transformational Leadership and Organizational Culture. Public Administration Quarterly, v. 17, n.1, p. 112-121, 1993.

BASS, B. M. Two decades of research and development in transformational leadership. European Journal of Work and Organizational Psychology, v.8, n.1, p.9-32, 1999.

BASS, B. M. The Bass handbook of leadership: theory, research, and managerial applications. 4. ed. New York: Free Press, 2008.

BAUER, M. W.; GASKELL, G. Pesquisa qualitativa com texto, imagem e som: um manual prático. 12. ed. Petrópolis: Vozes, 2014.

BERGAMINI, C. W. Liderança: administração do sentido. São Paulo: Atlas, 1994.

BRASIL. Lei no 11.326, de 24 de julho de 2006. Estabelece as diretrizes para a formulação da Política Nacional da Agricultura Familiar e Empreendimentos Familiares Rurais. Diário Oficial da União, Brasília, 25 jul. 2006.

CALAÇA, P. A; VIZEU, F. Revisitando a perspectiva de James MacGregor Burns: qual é a ideia por trás do conceito de liderança transformacional? Cadernos EBAPE.BR, v.13, n.1, p. 121-135, 2015.

CAMARGO, Brigido Vizeu; JUSTO, Ana Maria. IRAMUTEQ: um software gratuito para análise de dados textuais. Temas psicol., Ribeirão Preto, v. 21, n. 2, p. 513-518, dez. 2013.

Disponível em < http://pepsic.bvsalud.org/scielo.php?script=sci_arttext\&pid=S1413-389X2013 000200016\&lng=pt\&nrm=iso>. Acesso em: 19 de maio de 2020.

CHEMERS, M. M. Leadership research and theory: a functional integration. Group Dynamics. Theory, Research, and Practice, v.4, n.1, p.27-43, 2000.

CONAB. COMPANHIA NACIONAL DE ABASTECIMENTO. Acompanhamento da Safra Brasileira. 2020. Disponível em: <https://www.conab.gov.br/info-agro/safras/café>. Acesso em: 25 de outubro de 2020.

DOWNTON, J. V. Rebel leadership: Commitment and charisma in a revolutionary process. New York: Free Press, 1973.

DUARTE, R. Pesquisa qualitativa: reflexões sobre o trabalho de campo. Cadernos de Pesquisa, $\mathrm{n}$. 115, p. 139-154, 2002. 
EMATER. EMPRESA DE ASSISTÊNCIA TÉCNICA E EXTENSÃO RURAL DO ESTADO DE MINAS GERAIS. Projeto Observatório da Agricultura de Minas Gerais, 2019. Disponível em:

<http://portaldocafedeminas.emater.mg.gov.br/>. Acesso em 09 de maio de 2019.

FILETTO, F.; ALENCAR, E. Introdução e expansão do café na região do Sul de Minas Gerais. Organizações Rurais e Agroindustriais, v.3, n.1, p. 1-13, 2001.

FURTADO, C. A economia colonial no Brasil nos séculos XVI e XVII. São Paulo: Hucitec/ ABPHE, 2000.

GIL, A. C. Métodos e Técnicas de Pesquisa Social. 5. ed. São Paulo: Atlas, 1999.

GONÇALVES, M. N. C. Um estudo de Auto-Percepção de Enfermeiros Gestores. 2008. (Mestrado em Ciências Empresariais) - Universidade Fernando Pessoa, Porto, 2008.

GREMAUD, A. P.; SAES, F. A. M.; JÚNIOR, R. T. Formação Econômica do Brasil. São Paulo: Editora Atlas, 2008.

HATER, J. J.; BASS, B. M. Superiors' evaluations and subordinates' perceptions of transformational and transactional leadership. Journal of Applied Psychology, v. 6, n. 5, p. 695-702, 1988.

HOCHMAN, B.; NAHAS, F. X.; OLIVEIRA FILHO, R. S. D.; FERREIRA, L. M. Desenhos de pesquisa. Acta Cirúrgica Brasileira, v.20, p.2-9, 2005.

HU, J; WANG, Z; LIDEN, R. C; SUN, J. The influence of leader core self-evaluation on follower reports of transformational leadership. The Leadership Quarterly, v.23, n.5, p.860-868, 2012.

ISIDRO-FILHO, A; GUIMARÃES, T. A. Estilos de liderança e mecanismos de aprendizagem em organizações: análise de suas relações em uma organização financeira. Revista Eletrônica de Gestão Organizacional, v. 6, n. 3, p. 361-378, 2008.

MINAYO, M. C. S. (org.). Pesquisa Social: Teoria, método e criatividade. 28. ed. Petrópolis, RJ: Vozes, 2009.

NASCIMENTO, A. R. A.; MENANDRO, P. R. M. Análise lexical e análise de conteúdo: uma proposta de utilização conjugada. Estudos e Pesquisas em Psicologia, v.6, n.2, p.72-88, 2006.

NISSEN, M.; KAMEL, M.; SENGUPTA, K. Integrated analysis and design of knowledge systems and processes. Information Resources Management Journal, v. 13, n. 1, p. 24-43, Jan./Mar. 2000.

Northouse, P. G. (2010) Leadership: Theory and Practice (5a ed.). California, EUA: SAGE Publications, Inc.

OLIVEIRA, M. A. de; POSSAMAI, O.; VALENTINA, L. V. O. D. Perfil e tendências da liderança em uma empresa brasileira líder mundial de mercado. Production, v. 25, n. 2, p. 379-390, 2015.

SINGER, P. Desenvolvimento econômico e evolução urbana. São Paulo: Nacional, 1977. 
SOUZA, M. A. R. D.; WALL, M. L.; THULER, A. C. D. M. C.; LOWEN, I. M. V.; PERES, A. M. O uso do software IRAMUTEQ na análise de dados em pesquisas qualitativas. Revista da Escola de Enfermagem da USP, v.52, 2018.

STOGDILL, R. M. Personal Factors Associated with Leadership, A Survey of the Literature. Journal of Psychology, v. 25, n.1, p. 35-71, 1948.

TURANO. L. M.; CAVAZOTTE. F. Conhecimento científico sobre liderança: Uma análise bibliométrica do acervo do The Leadership Quarterly. Revista de Administração Contemporânea, v. 20, p. 434-457, 2016.

VALVERDE, O. A fazenda de café escravocrata no Brasil. Revista Brasileira de Geografia, Rio de Janeiro, v.29, n.1, p.1-58, jan./mar. 1967. 